\title{
What Do We Know About the Mental Health of Porn Performers? A Systematic Literature Review
}

Hannes Jarke

Centre for Business Research, Cambridge Judge Business School, University of Cambridge, Cambridge, UK

Hj318@cam.ac.uk

This is a post-print of the accepted manuscript, formatted by the author. The final version of this paper appears online in the Journal of Public Mental Health (ISSN: 1746-5729; ahead of print), published on $26^{\text {th }}$ January 2022, available via https://doi.org/10.1108/JPMH-07-2021-0083.

In accordance with publishing guidelines from Emerald, this postprint is made available under a Creative Commons Attribution Non-commercial International Licence 4.0 (CC BY-NC 4.0). As such, any reuse is allowed in accordance with the terms outlined by the licence and the author and publisher should always be credited in any reuse of this paper. To reuse the AAM for commercial purposes, permission should be sought by contacting permissions@emeraldinsight.com.

For the sake of clarity, commercial usage would be considered as, but not limited to: o Copying or downloading AAMs for further distribution for a fee;

o Any use of the AAM in conjunction with advertising;

o Any use of the AAM by for promotional purposes by for-profit organisations;

o Any use that would confer monetary reward, commercial gain or commercial exploitation. 


\section{What Do We Know About the Mental Health of Porn Performers? A Systematic Literature Review}

\section{Purpose}

Much has been debated about the impact pornography has on the health of those who consume it. But how is it affecting the people starring in it? Performing in porn is a unique profession which requires a person to have sex with other-often unfamiliar-people in front of a camera for a living comes with various kinds of stigma, and is accompanied by several health risks for professionals and amateurs. This brief report compiles available evidence on the mental health of performers in porn.

\section{Design/methodology/approach}

This paper employs the PRISMA approach to systematically review existing research from health sciences and psychology to provide an overview of what is known about mental health in porn performers.

\section{Findings}

Only three US studies examine the topic and none of them are recent, which may be due to porn performers being a population which has been described as hard to reach for researchers. The existing knowledge on performers' mental health is inconclusive at best, but points toward significantly poorer mental health and higher prevalence of mental disorders in some, but not others. New general research on the topic is needed to close this gap. More importantly, granular investigation into which populations are at risk of developing poor mental health and due to which circumstances is needed as a basis to support vulnerable performers.

\section{Originality}

This is the first systematic review compiling existing evidence on mental health of porn performers. An approach to address this lack of research is proposed.

Keywords: mental health; porn; porn performer; porn actor; porn actress; sex work 


\section{Introduction}

When five porn performers died by suspected suicides between late 2017 and early 2018, public discussion across media outlets followed. The Rolling Stone asked "Is the Porn Industry Doing Enough for Performers' Mental Health?” (Swann, 2018), online magazine Vice claimed that "Mental Illness Is Killing Porn Stars" (Severin, 2018), and Men's Health wondered: "Could Better Mental Health Care Have Saved August Ames?" (Dickson, 2017; August Ames was one of the performers who died with suspicion of suicide). Without granular data on how many porn performers exist in the US and how many have died by suicide, it is impossible to tell whether this occurrence was representative of increased suicide rates among performers. No matter the answer, the question whether porn performers suffer from poorer mental health or even higher prevalence of mental disorders is a reasonable and important one to answer, so that specific interventions may be developed to support performers - as it is being done in many other professions (World Health Organization [WHO], 2005).

Opinions on the topic in one direction persist: As with other forms of sex work, performing sexual acts in front of a camera for money comes with stigma (Evan-DeCicco and Cowan, 2001). One set of particularly strong assumptions, the Damaged Goods Hypothesis, is the belief that female performers are more likely to have been sexually abused in childhood, have more psychological problems, and use more drugs compared to other women. Although this hypothesis could not be confirmed by Griffith et al (2013a), stigma often prevails despite a lack of evidence. This can be especially problematic for those performers who are active on social media, as it puts them at risk for cyberbullying which can negatively impact mental health severely (Alhajji et al, 2019), going as far as being related to suicide attempts (Hinduja and Patchin, 2010). In addition, there are physical health risks unique to the profession: Porn performers report 
a high incidence of sexually transmitted diseases (STDs) — such as chlamydia and gonorrhoea - and low levels of condom use (Rodriguez-Hart et al, 2012, Javanbakht et $a l, 2017)$. Further, after having interviewed 28 female porn performers, Grudzen and colleagues conclude that "[f]emale performers in particular were especially vulnerable to multiple negative health consequences, including drug addiction, mental health problems, financial hardship, physical trauma, and negative social interactions" (Grudzen et al, 2009, p. 76).

If mental health in porn performers is indeed poorer and mental illnesses more prevalent, it is crucial to identify the specific circumstances and causes, so that contextspecific action can be taken to support performers in preventing and addressing mental ill-health. To provide a starting point for such studies, this review aims to evaluate whether mental health systematically differs within groups of porn performers, and if it is different from average mental health in the general population.

\section{Methods}

I employed the PRISMA method to conduct this systematic literature review (Moher et al, 2009), using the medical database PubMed and the psychology-specific database PsycINFO. For full transparency, the complete lists of search results for each included database are available openly in an online repository at https://osf.io/e4gwk. I did not set any restriction for the date on which articles were published and decided only to include articles written in English and German (my mother tongue). In addition, I searched all preprints in the Open Science Framework (OSF) database, as well as PsyArxiv and medRxiv-repositoriesfor preprints in the fields of psychology and medicine, respectively. The database searches occurred on the $22^{\text {nd }}$ of April 2020, any articles that 
fit the inclusion criteria which were added to the databases after that date are therefore not included in this review.

For this investigation, I define a porn performer as any person-independent of sex or gender-who professionally performs sexual acts on camera as a way to earn money (although it is irrelevant whether earning money is the primary motivation). This may include artists performing alone in front of a webcam, as well as performers who star in studio productions. I include any study, qualitative or quantitative, irrespective of research field, that investigates mental health, mental disorders, or well-being in porn performers. Articles which do not present an empirical investigation (such as essays or commentaries) were not included. As this is the first systematic review of this topic, the full spectrum of mental health is included, spanning studies on psychological well-being and quality of life to research concerning clinical aspects, i.e. mental disorders as defined by the WHO (2010) or the American Psychiatric Association (2013). Therefore, search terms included "porn”, “porn performer”, "porn star", “porn actor”, “porn actress", “mental health", "mental disorder", "mental illness", "well-being”, and "sex work". For the exact search strings and results, please see the search results document in the online repository.

\section{Results}

The searches yielded 119 results on PubMed and 616 results on PsycINFO, respectively, with a total of three articles included in this review (see Figure 1). I summarise the content and results below. No preprints relevant to this review were found in the OSF database, PsyArXiv, or medRxiv. 

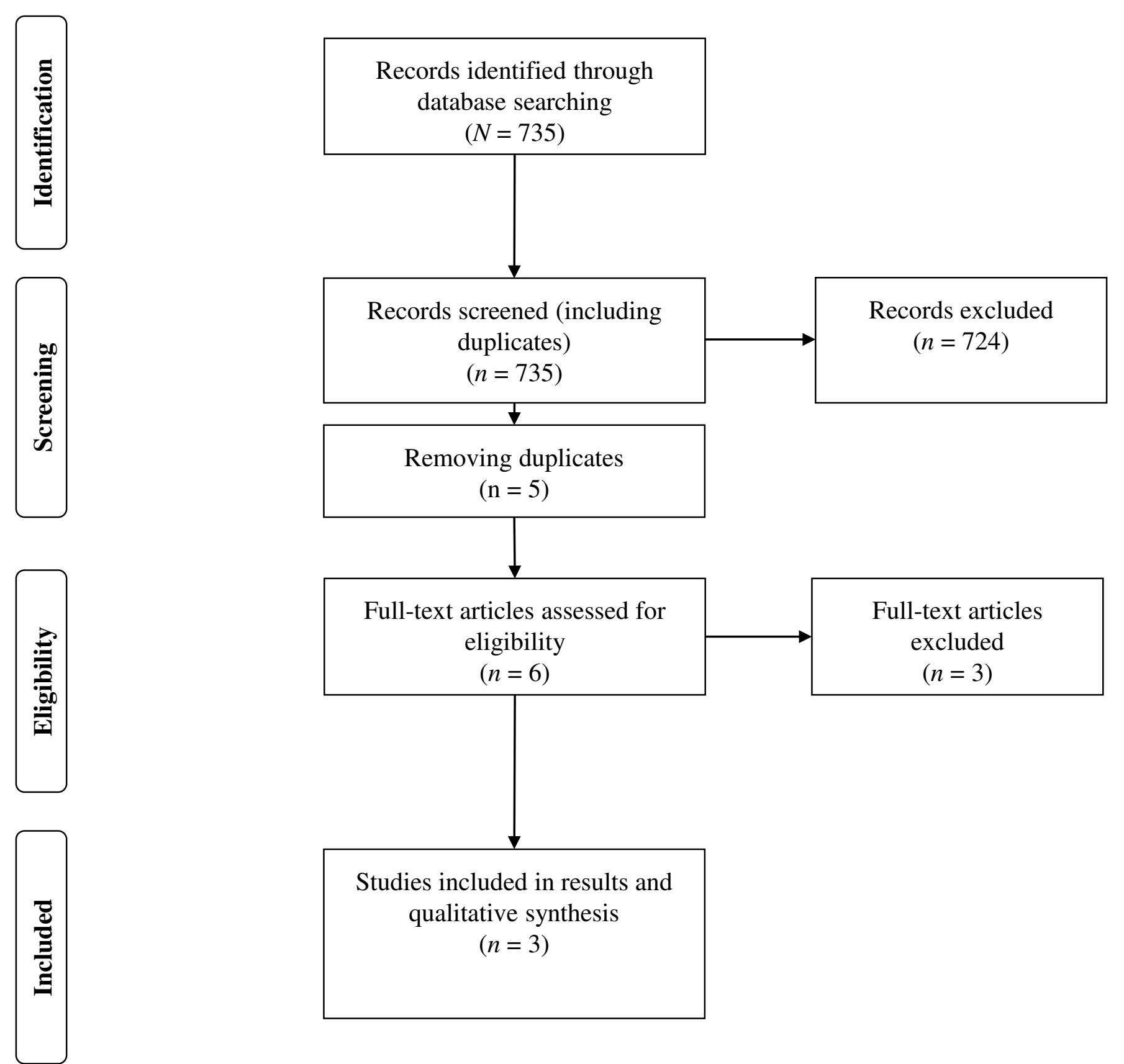

Figure 1. Flowchart of identified and included studies based on the PRISMA approach. 
Grudzen et al (2011) compared the mental health of 137 female performers to 1,773 women similar in age using items from the California Women's Health Survey. Based on their previous own qualitative work (Grudzen et al, 2009), the authors added questions regarding performers' history of working in adult films, work practices, illicit drug use, and HIV testing to the instrument. Participants were recruited online and were "eligible if they had performed in at least one adult film released in the past six months and they could be contacted via the Internet" (Grudzen et al, 2011, p. 640). Porn performers reported more days of poor mental health during the past 30 days than the women in the control group and were more likely to meet the criteria for currently being clinically depressed. During childhood, performers were more likely to have experienced rape, poverty, or having been placed in foster care. They were also more likely to have been forced into sex as adults, reported living in poverty, and having experienced domestic violence within the past 12 months more often. Overall, the study finds significantly worse mental health in performers, and higher rates in self-reported depression, compared to other women of similar age.

Griffith et al (2012) compared self-reported sexual behaviours, attitudes, selfesteem, quality of life (QoL), and drug use of 105 male porn actors to a matched sample of the same size. Most actors were heterosexual. Participants were considered a porn actor "if they were paid to work as an actor on at least one X-rated movie in which they participated in a sexual act" (Griffith et al, 2012, p. 256). They were recruited at the Adult Industry Medical Healthcare Foundation (AIM), a non-profit organization which provided STD testing and counselling to porn performers between 1998 and 2011, using convenience sampling. While performers reported receiving more enjoyment from sexual acts, they were also more worried to catch STD's compared to the control group. No differences were found in childhood sexual abuse incidences, or problematic alcohol use. 
Performers reported higher sexual satisfaction, body image, and feeling of physical safety, but did not significantly differ in overall QoL from the control group. They also reported higher self-esteem. The authors conclude that male porn performers were similar or even healthier by the psychological measures used but had tried more kinds of drugs in their lifetime.

A comparison between 118 bisexual and 58 heterosexual female performers regarding sexual behaviours and attitudes, QoL, as well as alcohol and drug use was conducted by Griffith et al (2013b). For this study, a person met the criteria of being a porn actress if she had received payment to perform a sexual act in at least one X-rated movie. Performers answered a survey about themselves, which they received at the AIM (see the previous paragraph). The study concludes that bisexual actresses have comparable to higher levels of well-being than heterosexual actresses. 


\section{Table 1}

\section{Extraction Table}

The sample size column indicates the description of porn performers, or the main group of interest, not the full sample size. Only statistically significant results are reported. PP = porn performer; QoL = Quality of Life; CSA = Child Sexual Abuse.

\begin{tabular}{|c|c|c|c|c|c|c|c|}
\hline & $\begin{array}{l}\text { Sample size } \\
\text { and age (in } \\
\text { years) }\end{array}$ & $\begin{array}{l}\text { Control } \\
\text { /comparison } \\
\text { group size } \\
\text { and age } \\
\end{array}$ & $\begin{array}{c}\text { Sample } \\
\text { description }\end{array}$ & Country & $\begin{array}{c}\text { Outcome } \\
\text { (Type of } \\
\text { Mental } \\
\text { Health) } \\
\end{array}$ & Measures & Outcomes \\
\hline $\begin{array}{l}\text { Grudzen et } \\
\text { al } 2011\end{array}$ & $\begin{array}{c}\mathrm{n}=134 \\
\text { females } \\
\mathrm{M}=27.8 \\
\mathrm{SD}=7.4\end{array}$ & $\begin{array}{l}\mathrm{n}=1,773 \\
\text { females } \\
\mathrm{M}=31.3 \\
\mathrm{SD}=5.9\end{array}$ & $\begin{array}{l}\text { Female porn } \\
\text { performers } \\
\text { compared to } \\
\text { California } \\
\text { women }\end{array}$ & $\begin{array}{c}\text { USA } \\
\text { (California) }\end{array}$ & $\begin{array}{c}\text { Mental } \\
\text { Health } \\
\text { status and } \\
\text { depression, } \\
\text { self- } \\
\text { reported }\end{array}$ & $\begin{array}{c}\text { California Women's } \\
\text { Health Survey (CWHS), } \\
\text { including the PHQ-8 for } \\
\text { depression }\end{array}$ & $\begin{array}{l}7.2 \text { days of poor mental health in PP } \\
\text { during the past } 30 \text { days compared to } 4.8 \\
\text { days in control group; } 33 \% \text { of PP's met } \\
\text { criteria for depression, } 13 \% \text { did in control } \\
\text { group. As children, PP were more likely to } \\
\text { having been raped ( } 37 \% \text { vs } 13 \% \text { ), lived in } \\
\text { poverty ( } 24 \% \text { vs } 12 \%) \text {, to have been } \\
\text { placed in foster care ( } 21 \% \text { vs } 4 \% \text { ). During } \\
\text { the past } 12 \text { months PPs were more likely to } \\
\text { live in poverty ( } 50 \% \text { vs } 34 \%) \text {, have } \\
\text { experienced domestic violence ( } 36 \% \text { vs. } \\
6 \% \text { ); and were more likely to have } \\
\text { experienced forced sex as adults ( } 27 \% \text { vs. } \\
9 \% \text { ) }\end{array}$ \\
\hline $\begin{array}{l}\text { Griffith et } \\
\text { al } 2012\end{array}$ & $\begin{array}{c}\mathrm{n}=105 \\
\text { males } \\
\mathrm{M}=35[19 ; 59] \\
\mathrm{SD}=\mathrm{N} / \mathrm{A}\end{array}$ & $\begin{array}{c}\mathrm{n}=105 \\
\text { males } \\
\mathrm{M}=\mathrm{N} / \mathrm{A}\end{array}$ & $\begin{array}{c}\text { Male porn } \\
\text { performers } \\
\text { compared to a } \\
\text { matched } \\
\text { sample (based } \\
\text { on age, } \\
\text { ethnicity, } \\
\text { marital status) }\end{array}$ & $\begin{array}{c}\text { USA } \\
\text { (California) }\end{array}$ & $\begin{array}{c}\text { Sexual } \\
\text { behaviour } \\
\text { and } \\
\text { attitudes, } \\
\text { Self- } \\
\text { Esteem, } \\
\text { QoL, } \\
\text { alcohol } \\
\text { and drug } \\
\text { use }\end{array}$ & $\begin{array}{c}10 \text { items on sexual } \\
\text { behaviour and attitudes, } \\
\text { Rosenberg Self-Esteem } \\
\text { Scale, World Health } \\
\text { Organization Quality-of- } \\
\text { Life Assessment } \\
\text { (WHOQOL), Michigan } \\
\text { Alcohol Screening Test } \\
\text { (SMAST), Texas } \\
\text { Christian University } \\
\text { (TCU) Drug Screen }\end{array}$ & $\begin{array}{l}\text { PP enjoyed sex more }(\mathrm{M}=9.67 \text { vs. } 8.87) \text {, } \\
\text { were more concerned about catching STDs } \\
\text { (M=7.56 vs. } 6.16) \text {, were less likely to use a } \\
\text { condom }(\mathrm{M}=76.13 \text { vs. } 87.41) \text {; regarding } \\
\text { QoL they reported higher sexual } \\
\text { satisfaction }(\mathrm{M}=14.08 \text { vs. } 13.06) \text {, a better } \\
\text { body image }(\mathrm{M}=14.33 \text { vs. } 13.70) \text {, as well } \\
\text { as a higher feeling of safety }(\mathrm{M}=13.70 \mathrm{vs.} \\
\text { 12.99); PP reported higher self-esteem } \\
(\mathrm{M}=34.26 \text { vs } 32.46) \text {; a comparison of } \\
\text { alcohol use revealed no significant } \\
\text { differences between the groups }\end{array}$ \\
\hline
\end{tabular}




\section{Griffith et}

al 2013b

$\mathrm{n}=176$

females

$\mathrm{M}=26[18 ; 50]$

$\mathrm{SD}=\mathrm{N} / \mathrm{A}$

Out of the

$\mathrm{n}=176,58$

heterosexual

PP were

compared to

118 bisexual

PP
See column on

control group
USA

(California)
Sexual

behaviours

and

attitudes,

work-

related

issues,

STDs,

CSA, QoL,

alcohol

and drug

use
10 items on sexual

behaviour and attitudes,

WHOQOL, SMAST
Bisexual PP enjoyed work more than heterosexual PP (M=8.8 vs. 8.0) and enjoyed sex more (M=9.6 vs. 8.9), no statistically significant difference in experience of CSA; QoL: Bisexual actresses reported higher values on the "positive" question ( $M=15.8$ vs. 14.7), and higher spirituality ( $\mathrm{M}=16.2$ vs. 14.9), but no difference was found in overall QoL,

No difference was found regarding alcohol use, a higher percentage of bisexual PP

had tried alcohol $\left(\chi^{2}(1)=6.71, p<.05\right.$, bisexual $98.3 \%$; heterosexual $89.7 \%)$, marijuana $\left(\chi^{2}(1)=5.22, p<.05\right.$, bisexual $83.9 \%$; heterosexual $69.0 \%$ ), and hallucinogens $\left(\chi^{2}(1)=4.90, p<.05\right.$, bisexual $41.4 \%$; heterosexual $24.6 \%$ ) 


\section{Discussion}

\section{Research regarding the mental health of porn performers is scarce and not up to date}

For 2019, Pornhub reported 42 billion visits to its website. A total of 6.83 million videos were uploaded to the site in the same year. While the consequences this amount of consumption has on its viewers' health have been investigated and discussed widely (e.g., Duffy et al, 2016), it is surprising that this review revealed only three papers that address porn performers' mental health and well-being, as well as no apparent work in progress (pre-prints) on the topic. In addition, all studies found were conducted in the US, limiting the validity of the evidence to the country, or at least similar (WEIRD) countries. This review clearly shows a lack of recent, generalizable, and replicable evidence regarding the mental health of porn performers, confirming previous claims by Bowring et al (2018). Notably, nothing can be inferred from the obtained results to performers who are self-producing and performing on platforms such as OnlyFans, as they could work under completely different circumstances.

\section{Situations can be entirely different for performers}

While Grudzen et al (2011) clearly find worse mental health and a higher incidence of having suffered through adverse experiences in female porn performers, two other studies (Griffith et al, 2012, Griffith et al, 2013b) do not show similar findings. Further, another relevant study by Griffith et al (2013a) was not among the results within the searched databases. The authors compared the responses of female performers to a matched sample from the general population and find no evidence for poorer mental health in performers. Why the investigations identified in this review find very different results is impossible to pinpoint. Different recruitment strategies may have yielded different samples, none of 
which may be representative of the profession as a whole. It is possible that either sample, both samples, or none of them are biased, as they may simply represent different groups of performers

The different results point towards a high diversity within the industry regarding both how production companies and agents treat performers, as well as within performers and their reasons to join the profession. While the job may be very fruitful for those with specific personalities and who are open about their work, as well as those who work with legitimate production companies, people—especially women—from low socio-economic background may be lured into a glamorous looking life by self-declared agents who act similar to a pimp (Grudzen et al, 2009). Such "agents" may exploit inexperienced performers and hold power over them by being the ones who have the contacts within the industry and being able to expose their work to family. This is obviously an entirely different situation than that of a young person with a supportive environment deliberately choosing to work in porn.

Based on the little evidence available, performing in porn may not be related to mental health at all for some, while for others there is a very strong connection, in which case other moderating factors need to be explored and later leveraged to performers' advantage through policy. Specifically, the question remains whether performing in porn as such is a risk factor for poor mental health, or whether risk factors are almost entirely due to work environment and stigma-related issues, such as online bullying. It further remains unknown if working as a porn performer may only affect specific groups' mental health: For example, men may have an entirely different experience than women; while transsexual people may find themselves in yet other unique situations with regards to how they are perceived and treated, both positive and negative (Pezzutto, 2020). It is clear that 
the current available evidence is not sufficient, rather outdated, and lacking replication efforts to base action on.

\section{Addressing the lack of evidence}

The results point towards a mandate for more granular research into porn performers' mental health, specifically taking into account public calls from performers themselves, together with anecdotal evidence for violent abuse towards female performers in the industry (Boyle, 2011). This lack of available information and the vast diversity of pornographic media calls for an entirely new approach to study the mental health of performers and ensuring the inclusion of their diverse subgroups. This poses a great challenge, given that the porn industry has previously been found to be hard to reach for research (Griffith et al, 2013b) - although it is unknown whether the reasons for this low engagement, also in scientific debates, is intentional or accidental (West, 2020).

Research approaches should consider the large number of performers who record at home or outdoors and use services such as OnlyFans and Patreon (platforms where creators own their content and sell it directly to subscribers, including personalised content), to produce pornography and other erotic or fetish content on their own, or with little/non-professional help. Such approaches may also explore potential differences in live webcam performers or those interacting with audiences, as "amateur" performers often have different experiences with their work than professionals (O’Neal, 2016), specifically those performers specialising in a niche.

I support the notion by Bowring et al (2018) of identifying key topics important to performers and would enquire further about well-being and mental health specifically. However, this should only be the starting point in a grounded theory guided research project: that is, an iterative process of building a framework driven solely by new data- 
both qualitative and quantitative - to avoid bias from existing assumptions (Chun Tie, Birks, and Francis, 2019). Such an endeavour would start by interviewing self-producing performers working on platforms such as OnlyFans and Patreon, as well as performers who act in studio productions. Another potential advantage from a logistical point of view is that these self-managing performers often have contact details on their online profiles, which may make it easier to get in touch with them and could potentially even provide a "foot in the door" of a network of performers. While performers may still be a hard-toreach population, seeking out those who openly discuss the topic on social media (especially twitter) could further be an opportunity. Even though such a recruitment strategy can result in a biased sample, it could provide insights into the factors and actors that are crucial to performers' mental health. As also suggested for self-managing performers, this may provide a first step to getting in touch with a larger network.

Participatory research approaches have previously been suggested as a useful tool to engage and involve populations directly (Bergold and Thomas, 2012). Such an approach could help to establish a successful outreach and permanent cooperation with industry workers - not limited to performers, but also including producers, agents, camera personnel, technicians - and groups of self-managing and self-producing performers. Both, semi-structured one-on-one interviews, as well as focus groups could complement each other in determining topics crucial to performers' everyday lives, challenges, and work environment. Based on what can be learned from such interviews, quantitative measures may be derived, adequate, validated measures for mental health and well-being added, and groups compared to identify possible reasons for problematic findings. In addition, stakeholders, as well as partners of performers should be interviewed to further map the environment of performers. 
Such detailed information and a clearer picture of the environments performers manoeuvre in — and which factors are directly related to their mental health—could help policymakers in building evidence-based interventions to support performers, improve well-being, and prevent mental illness. It further may even make issues visible that require political or judicial changes. Research on mental health and well-being with regards to peoples' profession and workplace has, for good reason, become more and more common - it is time for it to be investigated thoroughly for performers in porn.

\section{Funding details}

No funding has been received to conduct this review.

\section{Disclosure statement}

The author declares no conflicts of interest.

\section{References}

Alhajji, M., Bass, S. and Dai, T. (2019). “Cyberbullying, Mental Health, and Violence in Adolescents and Associations With Sex and Race: Data From the 2015 Youth Risk Behavior Survey.", Global Pediatric Health, Vol. 6. $2333794 X 1986888$. https://doi.org/10.1177/2333794x19868887.

American Psychiatric Association. (2013). Diagnostic and statistical manual of mental disorders (5th ed.). Washington, DC: American Psychiatric Association.

Bergold, J. and Thomas, S. (2012). "Participatory Research Methods: A Methodological Approach in Motion.” Historical Social Research, Vol. 37 No. 4, pp. 191-222. https://doi.org/10.17169/fqs-13.1.1801.

Bowring, J., Leavey, C., Ross-Houle, K., Carline, A. and Gunby, C. (2018). "The UK Adult Film Performer Project-a Case for Being pro-Performer Voice." Porn Studies, Vol. 5 No. 4, pp. 457-60. https://doi.org/10.1080/23268743.2018.1524091.

Boyle, K. (2011). "Producing Abuse: Selling the Harms of Pornography." Women's Studies International Forum, Vol. 34 No. 6, pp. 593-602. https://doi.org/10.1016/j.wsif.2011.09.002" https://doi.org/10.1016/j.wsif.2011.09.002. 
Chun Tie, Y., Birks, M., and Francis, K. (2019). Grounded theory research: A design framework for novice researchers. SAGE Open Medicine, Vol. 7, pp. 1-8. https://doi.org/10.1177/2050312118822927

Dickson, E.J. (2017). Could Better Mental Health Care Have Saved August Ames? Men's Health. 7 December. https://www.menshealth.com/health/a19544705/august-ames-porn-star-suicide$\underline{\text { mental-health-care/ }}$

Duffy, A., Dawson, D.L. and das Nair, R. (2016). "Pornography Addiction in Adults: A Systematic Review of Definitions and Reported Impact". The Journal of Sexual Medicine, Vol. 13 No. 5, pp. 760-777. https://doi.org/10.1016/j.jsxm.2016.03.002

Evans-Decicco, J.A. and Cowan, G. (2001). "Attitudes Toward Pornography and the Characteristics Attributed to Pornography Actors" Sex Roles Vol. 44 No. 5/6, pp. $351-61$.

Griffith, J.D., Hammond, B., Mitchell, S., and Hart, C.L. (2013b). "Sexual Behaviors and Attitudes, Quality of Life, and Drug Use: A Comparison Between Bisexual and Heterosexual Pornography Actresses.” Journal of Bisexuality, Vol. 13 No. 1, pp. 4-20. https://doi.org/10.1080/15299716.2013.755729.

Griffith, J.D., Mitchell, S., Hammond, B. Gu, L.L. and Hart, C.L. (2012). “A Comparison of Sexual Behaviors and Attitudes, Self-Esteem, Quality of Life, and Drug Use Among Pornography Actors and a Matched Sample." International Journal of Sexual Health, Vol. 24 No. 4, pp. 254-66. https://doi.org/10.1080/19317611.2012.710183.

Griffith, J.D., Mitchell, S., Hart, C.L., Adams, L.T. and Gu, L.L. (2013a). "Pornography Actresses: An Assessment of the Damaged Goods Hypothesis." Journal of Sex Research, Vol. 50 No. 7, pp. 621-32. https://doi.org/10.1080/00224499.2012.719168.

Grudzen, C.R., Meeker, D., Torres, J.M., Qingling, D., Morrison, S. et al. (2011). "Comparison of the Mental Health of Female Adult Film Performers and Other Young Women in California.” Psychiatric Services, Vol. 62, No. 6), pp. 639-45. https://doi.org/10.1176/ps.62.6.pss6206_0639

Grudzen, C.R., Ryan, G., Margold, W., Torres, J. and Gelberg, L. (2009). "Pathways to Health Risk Exposure in Adult Film Performers." Journal of Urban Health Vol. 86 No. 1, pp. 67-78. https://doi.org/10.1007/s11524-008-9309-4.

Hinduja, S., and Patchin, J.W. (2010). "Bullying, Cyberbullying, and Suicide.” Archives of Suicide Research, Vol. 14 Np. 3, pp. 206-21. https://doi.org/10.1080/13811118.2010.494133.

Javanbakht, M., DIllavou, M., Rigg, R.W., Kerndt,P.R. and Gorbach, P.M. (2017). "Transmission Behaviors and Prevalence of Chlamydia and Gonorrhea among Adult Film Performers.” Sexually Transmitted Diseases, Vol. 44 No. 3, pp. 18186. https://doi.org/10.1097/OLQ.0000000000000567. 
Moher, D., Liberati, A., JTetzlaff, J., Altman, D.G. et al. (2009). "Preferred Reporting Items for Systematic Reviews and Meta-Analyses: The PRISMA Statement." PLoS Medicine, Vol. 6 No.7. https://doi.org/10.1371/journal.pmed.1000097.

O’Neal, E.N. (2006). "Zooming in on the money shot: an exploratory quantitative analysis of pornographic film actors." PhD diss., University of Central Florida.

Pezzuto, S. (2020). Professionalism, pay, and the production of pleasure in trans porn. Transgender Studies Quarterly, 7(2), 262-267. https://doi.org/10.1215/232892528143435

Rodriguez-Hart, C., Chitale, R.A., Rigg, R., Goldstein, B.Y., Kerndt, P.R. and Tavrow, P. (2012). "Sexually Transmitted Infection Testing of Adult Film Performers: Is Disease Being Missed?” In Sexually Transmitted Diseases, Vol. 39, pp. 987-92. https://doi.org/10.1097/OLQ.0b013e3182716e6e.

Severin, K. (2018). "Mental Illness Is Killing Porn Stars and the Industry Is Taking Action”. Vice. 26 May 26. https://www.vice.com/en_uk/article/59q955/mentalillness-is-killing-porn-stars-and-the-industry-is-taking-action

Swann, J. (2018). "Is the Porn Industry Doing Enough for Performers' Mental Health?" Rolling Stone. 18 January. https://www.rollingstone.com/culture/culturefeatures/is-the-porn-industry-doing-enough-for-performers-mental-health-200072/

West, C., Imbert, J., \& Studies, I. (2020). Dancing in the Shadows of the Outer Limits : An Exploration of the Experiences of Female Pornography Performers and Feminist Discourses on Their Experiences. PhD diss., Dublin City University.

WHO. (2005). Mental Health policies and programmes in the workplace. Geneva: WHO.

WHO. (2010). The ICD-10 classification of mental and behavioural disorders: clinical descriptions and diagnostic guidelines. Geneva: WHO. 